\title{
Testing price equations
}

\author{
Ray C. Fair * \\ Cowles Foundation and International Center for Finance, Yale University, New Haven, CT 06520-8281, USA
}

\section{A R T I C L E I N F O}

\section{Article history:}

Received 17 September 2007

Accepted 27 June 2008

Available online 5 July 2008

\section{JEL classification:}

E31

Keywords:

Price equations

NAIRU

\begin{abstract}
A B S T R A C T
How inflation and unemployment are related in both the short run and long run is perhaps the key question in macroeconomics. This paper tests various price equations using quarterly U.S. data from 1952 to the present. Issues treated are the following. (1) Estimating price and wage equations in which wages affect prices and vice versa versus estimating "reducedform" price equations with no wage explanatory variables. (2) Estimating price equations in $(\log )$ level terms, first difference (i.e., inflation) terms, and second difference (i.e., change in inflation) terms. (3) The treatment of expectations. (4) The choice and functional form of the demand variable. (5) The choice of the cost-shock variable. The results suggest that the best specification is a price equation in level terms imbedded in a price-wage model, where the wage equation is also in level terms. The best cost-shock variable is the import price deflator, and the best demand variable is the unemployment rate. There is some evidence of a nonlinear effect of the unemployment rate on the price level at low values of the unemployment rate. Many of the results in this paper are contrary to common views in the literature, but the empirical support for them is strong.
\end{abstract}

(c) 2007 Elsevier B.V. All rights reserved.

\footnotetext{
For presentation at "The Phillips Curve and the Natural Rate of Unemployment," June 3-4, 2007, Kiel Institute for World Economics, Kiel, Germany.

* Tel.: +12034323715.

E-mail address: ray.fair@yale.edu

URL: http://fairmodel.econ.yale.edu
} 


\section{Introduction}

How inflation and unemployment are related in both the short run and long run-i.e., the specification of price equations-is perhaps the key question in macroeconomics. As a recent review of price equations by Rudd and Whelan (2007) shows, there is certainly no consensus view of the best explanation of inflation. This paper tests various price equations using quarterly U.S. data from 1952 to the present. The aim is to see which price equation best explains the historical data. Some of the questions considered are the following. (1) Is it better to estimate price and wage equations in which wages affect prices and vice versa or to estimate "reduced-form" price equations with no wage explanatory variables? (2) Is it best to estimate price equations in (log) level terms, in first difference (i.e., inflation) terms, or in second difference (i.e., change in inflation) terms? (3) Is it better to take expectations to be rational or not? (4) What is the best choice and functional form for the demand variable? (5) What is the best choice for the cost-shock variable?

The results in this paper suggest that the best specification is a price equation in level terms imbedded in a price-wage model, where the wage equation is also in level terms. The best cost-shock variable is the import price deflator and the best demand variable is the unemployment rate. The functional form for the unemployment rate is likely to be nonlinear at very low values of the unemployment rate, but the functional form is hard to estimate because there are so few observations with very low values. However, some evidence of a nonlinear functional form has been found. Many of the results in this paper are contrary to common views in the literature, but it will be seen that the empirical support for them is strong.

This paper begins with the new-Keynesian Phillips curve (NKPC) in Section 2. This section argues that FIML estimation of this equation is the obvious procedure to use if expectations are rational. Fuhrer's (1997) model is reestimated by FIML using updated data, and the coefficient estimate of the expected future inflation variable is insignificant. Lindé (2005), on the other hand, estimates his model by FIML and does find a significant estimate. The evidence for the NKPC is thus mixed, and more work is needed before any judgement can be made. Section 3 examines the reduced-form price equation in which inflation depends on past inflation, demand, and cost shocks. This model is sometimes called the "triangle" model because of the three main effects on inflation. The results in this section show that the dynamics of this equation are rejected. Section 4 then presents a pricewage model, with a price equation and a wage equation, which is shown to be more accurate than a price equation alone. Section 4 also examines the sensitivity of the results to different measures of demand and cost shocks and to different functional forms of the demand variable.

The main conclusion of this paper is that the best explanation of inflation in terms of explaining the U.S. historical data is a model in which the log of the price level depends on the lagged log price level, the log of the wage rate, the log of the price of imports, the unemployment rate, a constant term, and a time trend and in which the log of the wage rate depends on the lagged log wage rate, the log of the price level, the lagged log of the price level, a constant term, and a time trend. This specification is not new. It is currently part of my macroeconometric model-Fair, 2004 - and it is close to the specification that existed in the version of the model 24 years ago-Fair (1984), U.S. equations (10) and (16).

\section{The new-Keynesian Phillips curve}

\section{A typical version of the NKPC is}

$$
\pi_{t}=\beta_{1} E_{t} \pi_{t+1}+\beta_{2} y_{t}+\varepsilon_{t},
$$

where $\pi$ is the inflation rate and $y$ is the output gap. $E_{t}$ denotes expectations based on information at time $t$. Expectations are assumed to be rational. This equation is part of the new-Keynesian (NK) model, and there is a huge literature on it. There is also a 'hybrid' version of this equation that is popular, which adds the lagged inflation rate to the equation

$$
\pi_{t}=\beta_{1} E_{t} \pi_{t+1}+\beta_{2} y_{t}+\beta_{3} \pi_{t-1}+\varepsilon_{t},
$$

where $\beta_{1}+\beta_{3}$ is usually constrained to be 1 . 
Rudd and Whelan $(2005,2006,2007)$ in a series of papers have shown that $E_{t} \pi_{t+1}$ does not have an important influence on current inflation given the model and the assumption that expectations are rational. Their results are robust to different measures of the output gap, including the use of the labor share, as Galí and Gertler (1999) advocate.

Rudd and Whelan's tests do not involve the full information maximum likelihood (FIML) estimation of Eq. (2). In fact, there has been little attempt in the literature to use FIML in this context. Most of the direct estimates of Eq. (2) involve GMM. For example, Blanchard and Gali (2005) estimate Eq. (2) with the change in the PPI raw materials index relative to the GDP deflator added, and they use as instruments four lags each of inflation, the demand variable (the unemployment rate), and the raw materials index variable. The problem with this choice of instruments is that except for inflation lagged once, the lagged values are not part of the model and so theoretically are not appropriate to use. To use these lags, one has to argue that the equation is part of a larger model in which the lags appear, but this is not very satisfying. A stronger test of the equation would be to specify the rest of the model and estimate the model by FIML, where the assumption that $E_{t} \pi_{t+1}$ is model consistent-i.e., that expectations are rational—is imposed.

Fuhrer (1997) estimates a version of (2) by FIML with two vector autoregressive (VAR) equations added to the model. He estimates

$$
\pi_{t}=\beta_{1}\left[\left(\pi_{t-1}+\pi_{t-2}+\pi_{t-3}\right) / 3\right]+\left(1-\beta_{1}\right)\left[E_{t}\left(\pi_{t+1}+\pi_{t+2}+\pi_{t+3}\right) / 3\right]+\beta_{2} y_{t}+\varepsilon_{t},
$$

plus a VAR equation for $y_{t}$ and a VAR equation for the federal funds rate. Each of the two VAR equations includes a constant term and four lagged values each of inflation, the output gap, and the federal funds rate. The sample period is 1966:1-1994:1. Fuhrer first estimates the two VAR equations by ordinary least squares first and then takes these as fixed for purposes of estimating Eq. (3).

Fuhrer's model is linear, and he used a linear technique for the FIML estimates. This model can also be estimated by the method in Fair and Taylor (1990) (FT). Although the FT method is more computational intensive for linear models than are linear techniques, it can handle nonlinear models and thus may be useful in future research.

I wanted to duplicate Fuhrer's results using the FT method, but he lost the original data. He sent me a later data set (but the same sample period) and kindly reestimated his model using his method and this data set. I was able to duplicate these new results using the FT method. The original estimate of $\beta_{1}$ was 0.80 and it is now 0.95 , and the original estimate of $\beta_{2}$ was 0.12 and it is now 0.13 . Fuhrer used the $\mathrm{BHHH}$ algorithm for computing the variance-covariance matrix of the coefficient estimates, and I used the inverse of the second derivatives (computed numerically) of the log of the likelihood function. This makes some difference in the estimated standard errors. I get a standard error for the estimate of $\beta_{1}$ of 0.42 and Fuhrer gets 0.11 . For the estimate of $\beta_{2}$ the respective estimated standard errors are 0.12 and 0.03 . In either case, however, the estimate of $\beta_{1}$ is not significantly different from 1.0 and thus the expected future inflation variable is not significant. This FIML result is consistent with the results of Rudd and Whelan in that there is no evidence that expectations of future inflation affect current inflation conditional on expectations being rational. Kurmann (2007), on the other hand, using an approach similar to Fuhrer's, does find significant effects.

Neither Fuhrer's nor Kurmann's model is completely structural in that there are VAR equations in the model. One example in the literature of Eq. (2) estimated by FIML within a completely structural model is Lindé (2005). He estimates using FIML a version of Eq. (2) in the context of the NK model. He adds some lags to the model that are not strictly part of the NK model, but the model is, however, a complete system that can be estimated by FIML. The three-equation model is

$$
\begin{aligned}
& \pi_{t}=\beta_{1} E_{t} \pi_{t+1}+\left(1-\beta_{1}\right) \pi_{t-1}+\beta_{2} y_{t}+\varepsilon_{t}, \\
& y_{t}=\alpha_{1} E_{t} y_{t+1}+\left(1-\alpha_{1}\right) \sum_{i=1}^{4} \delta_{i} y_{t-i}+\alpha_{2}\left(r_{t}-E_{t} \pi_{t+1}\right)+v_{t}, \\
& r_{t}=\left(1-\sum_{i=1}^{3} \rho_{i}\right)\left(\theta_{1} \pi_{t}+\theta_{2} y_{t}\right)+\sum_{i=1}^{3} \rho_{i} r_{t-i}+w_{t},
\end{aligned}
$$

where $r$ is the nominal interest rate and $\sum_{i=1}^{4} \delta_{i}=1$. The data are quarterly U.S. data for the 1960:1-1997:4 period. 
The important question for present purposes in Lindé's model is whether $\beta_{1}$ is different from zero. Lindé finds this to be so. The estimate of $\beta_{1}$ is 0.282 with an estimated standard error (SE) of 0.057 using GDP for output and 0.452 with an SE of 0.065 using non-farm business output (NFB) for output. Some of the SEs are sensitive to the use of GDP or NFB data. The estimate of $\alpha_{2}$ using GDP data is 0.087 with an SE of 0.083 , which is not significant, and the estimate using NFB data is 0.156 with an SE of 0.016 , which is highly significant. The estimate of $\theta_{2}$ using GDP data is 0.995 with an SE of 0.526 , which is not significant, and the estimate using NFB data is 1.017 with an SE of 0.170 , which is highly significant. These are large differences in the estimated standard errors given that the coefficient estimates are fairly similar. This suggests that the estimated covariance matrix may be sensitive to small changes in the data or that there is a rounding error problem.

I tried to estimate Lindé's model by FIML using the FT method with data supplied by Lindé, but with no success. I could duplicate his results using the linear technique that he supplied, but I was unable to solve the model with enough precision using the FT method to allow estimation to proceed. Whether this sensitivity is related to the possible estimated covariance matrix sensitivity mentioned above is unclear. An interesting question for future research is whether the significance of the estimate of $\beta_{1}$ holds up with alternative versions of the NK model. If the FT method can be found to work on alternative versions, the models need not be constrained to be linear. Such models could be added to the models used in Sections 3 and 4 to see how well they explain the data.

The results so far using the NKPC equation are thus mixed. Rudd and Whelan's work and the estimates of Fuhrer's model find no evidence that expectations of future inflation affect current inflation conditional on expectations being rational. Kurmann does find an effect, and Lindé obtains a significant estimate of $\beta_{1}$ in Eq. (4). More work is needed estimating completely structural models by FIML before much can be said. For the rest of this paper the rational expectations assumption will not be used.

\section{The triangle model ${ }^{1}$}

Prior to the NKPC equation, the standard inflation equation took inflation to depend on past inflation, demand-usually the unemployment rate-and cost shocks. This is sometimes called the triangle model because of the three basic determinants of inflation. A simple version of the equation is

$$
\pi_{t}-\pi_{t-1}=\beta\left(u_{t}-u^{*}\right)+\gamma s_{t}+\varepsilon_{t}, \quad \beta<0, \quad \gamma>0,
$$

where $u$ is the unemployment rate and $s$ is a cost-shock variable. $u^{*}$, sometimes call the natural rate or the NAIRU, is the unemployment rate at which the inflation rate does not change aside from changes in $s_{t}$ and $\varepsilon_{t}$. A more general version of Eq. (7) is

$$
\pi_{t}=\alpha+\sum_{i=1}^{n} \delta_{i} \pi_{t-i}+\sum_{i=0}^{m} \beta_{i} u_{t-i}+\sum_{i=0}^{q} \gamma_{i} s_{t-i}+\varepsilon_{t}, \quad \sum_{i=1}^{n} \delta_{i}=1 .
$$

For this specification the NAIRU is $-\alpha / \sum_{i=0}^{m} \beta_{i}$.

The two dynamic restrictions in Eq. (8) are that (1) the $\delta_{i}$ coefficients sum to 1 (or in Eq. (7) that the coefficient of $\pi_{t-1}$ is 1 ) and (2) the (log) price level never appears as a separate variable but only in change form as the rate of inflation. It is straightforward to test these two restrictions. Let $p_{t}$ denote the log of the price level, where $\pi_{t}=p_{t}-p_{t-1}$. Using this notation, Eqs. (7) and (8) can be written in terms of $p$ rather than $\pi$. Eq. (7), for example, becomes

$$
p_{t}=2 p_{t-1}-p_{t-2}+\beta\left(u_{t}-u^{*}\right)+\gamma s_{t}+\varepsilon_{t} .
$$

In other words, Eq. (7) can be written in terms of the current and past two price levels, ${ }^{2}$ with restrictions on the coefficients of the past two price levels. Similarly, if in Eq. (8) $n$ is, say, 4, the

\footnotetext{
${ }^{1}$ The results in this section are updates of those in Fair (2004, Chapter 4).

2 "Price level" in this paper always refers to the log of the price level.
} 
equation can be written in terms of the current and past five price levels, with two restrictions on the coefficients of the five past price levels. (Denoting the coefficients on the past five price levels as $a_{1}$ through $a_{5}$, the two restrictions are $a_{4}=5-4 a_{1}-3 a_{2}-2 a_{3}$ and $a_{5}=-4+3 a_{1}+2 a_{2}+a_{3}$.) These restrictions can be tested by simply adding $p_{t-1}$ and $p_{t-2}$ to the equation and testing whether they are jointly significant. An equivalent test is to add $\pi_{t-1}$ (i.e., $p_{t-1}-p_{t-2}$ ) and $p_{t-1}$. Adding $\pi_{t-1}$ breaks the restriction that the $\delta_{i}$ coefficients sum to 1 , and adding both $\pi_{t-1}$ and $p_{t-1}$ breaks the summation restriction and the restriction that each price level is subtracted from the previous price level before entering the equation.

Eq. (8) was used for the tests, where $s_{t}$ in the equation is postulated to be $p m_{t}-\tau_{0}-\tau_{1} t$, the deviation of $p m$ from a trend line. $p m$ is the log of the price of imports, which is taken here to be the cost-shock variable. The estimation period is 1955:3-2006:2, 204 observations. All the data used in this paper are discussed in Appendix A. The price variable is the private non-farm deflator. $n$ is taken to be 12 and $m$ and $q$ are taken to be 2 . This fairly general specification regarding the number of lagged values is used to lessen the chances of the results being due to a particular choice of lags.

Eq. (8) was estimated in the following form:

$$
\Delta \pi_{t}=\lambda_{0}+\lambda_{1} t+\sum_{i=1}^{n-1} \theta_{i} \Delta \pi_{t-i}+\sum_{i=0}^{m} \beta_{i} u_{t-i}+\sum_{i=0}^{q} \gamma_{i} p m_{t-i}+\varepsilon_{t},
$$

where $\lambda_{0}=\alpha+\left(\gamma_{0}+\gamma_{1}+\gamma_{2}\right) \tau_{0}+\left(\gamma_{0}+2 \gamma_{1}+3 \gamma_{2}\right) \tau_{1}$ and $\lambda_{1}=\left(\gamma_{0}+\gamma_{1}+\gamma_{2}\right) \tau_{1} . \alpha$ and $\tau_{0}$ are not identified in Eq. (10), but for purposes of the tests this does not matter. For reference it will be useful to write Eq. (10) with $\pi_{t-1}$ and $p_{t-1}$ added:

$$
\begin{aligned}
\Delta \pi_{t}= & \lambda_{0}+\lambda_{1} t+\sum_{i=1}^{n-1} \theta_{i} \Delta \pi_{t-i}+\sum_{i=0}^{m} \beta_{i} u_{t-i}+\sum_{i=0}^{q} \gamma_{i} p m_{t-i} \\
& +\phi_{1} \pi_{t-1}+\phi_{2} p_{t-1}+\varepsilon_{t} .
\end{aligned}
$$

The results of estimating Eqs. (10) and (11) are presented in Table 1. They show that when $\pi_{t-1}$ and $p_{t-1}$ are added, the standard error of the equation falls from 0.00356 to 0.00329 . The $t$-statistics for the two variables are -5.88 and -5.04 , respectively, and the $\chi^{2}$ value for the hypothesis that the coefficients of both variables are zero is $31.26 .^{3}$

The $5 \%$ critical $\chi^{2}$ value for two degrees of freedom is 5.99 and the $1 \%$ critical value is 9.21 . If the $\chi^{2}$ distribution is a good approximation to the actual distribution of the " $\chi^{2}$ " values, the two variables are highly significant and thus the dynamics of Eq. (10) are strongly rejected. If, however, Eq. (10) is in fact the way the price data are generated, the $\chi^{2}$ distribution may not be a good approximation for the test. ${ }^{4}$ To check this, the actual distribution was computed using the following procedure.

First, estimate Eq. (10), and record the coefficient estimates and the estimated variance of the error term. Call this the "base" equation. Assume that the error term is normally distributed with mean zero and variance equal to the estimated variance. Then:

1. Draw a value of the error term for each quarter. Add these error terms to the base equation and solve it dynamically to generate new data for $p$. Given the new data for $p$ and the data for $u$ and $p m$ (which have not changed), compute the $\chi^{2}$ value as in Table 1 . Record this value.

2. Do step 11000 times, which gives $1000 \chi^{2}$ values. This gives a distribution of 1000 values.

3. Sort the $\chi^{2}$ values by size, choose the value above which $5 \%$ of the values lie and the value above which $1 \%$ of the values lie. These are the $5 \%$ and $1 \%$ critical values, respectively.

These calculations were done, and the $5 \%$ critical value was 18.88 and the $1 \%$ critical value was 24.30. These values are considerably larger than the critical values from the actual $\chi^{2}$ distribution

\footnotetext{
${ }^{3}$ Note that there is a large change in the estimate of the coefficient of the time trend when $\pi_{t-1}$ and $p_{t-1}$ are added. The time trend is serving a similar role in Eq. (11) as the constant term is in Eq. (10).

${ }^{4}$ If the $\chi^{2}$ distribution is not a good approximation, then the t-distribution will not be either, and so standard tests using the $t$-statistics in Table 1 will not be reliable. The following analysis focuses on correcting the $\chi^{2}$ critical values, and no use of the $t$-statistics is made.
} 
Table 1

Estimates of Eqs. (10) and (11): The left-hand side variable is $\Delta \pi_{t}$

\begin{tabular}{|c|c|c|c|c|}
\hline \multirow[b]{2}{*}{ Variable } & \multicolumn{2}{|l|}{ Eq. (10) } & \multicolumn{2}{|l|}{ Eq. (11) } \\
\hline & Estimate & t-stat. & Estimate & $t$-stat. \\
\hline cnst & 0.0048 & 1.22 & -0.0378 & -3.83 \\
\hline$t$ & 0.0000002 & 0.01 & 0.0002233 & 4.45 \\
\hline$u_{t}$ & -0.312 & -3.01 & -0.227 & -2.34 \\
\hline$u_{t-1}$ & 0.096 & 0.53 & 0.053 & 0.31 \\
\hline$u_{t-2}$ & 0.120 & 1.11 & 0.023 & 0.23 \\
\hline$p m_{t}$ & 0.039 & 2.36 & 0.050 & 3.22 \\
\hline$p m_{t-1}$ & 0.032 & 1.02 & 0.025 & 0.86 \\
\hline$p m_{t-2}$ & -0.070 & -3.94 & -0.043 & -2.32 \\
\hline$\Delta \pi_{t-1}$ & -0.872 & -12.97 & -0.367 & -3.46 \\
\hline$\Delta \pi_{t-2}$ & -0.678 & -8.39 & -0.304 & -3.05 \\
\hline$\Delta \pi_{t-3}$ & -0.505 & -5.95 & -0.250 & -2.70 \\
\hline$\Delta \pi_{t-4}$ & -0.326 & -3.75 & -0.153 & -1.71 \\
\hline$\Delta \pi_{t-5}$ & -0.359 & -4.28 & -0.231 & -2.70 \\
\hline$\Delta \pi_{t-6}$ & -0.287 & -3.50 & -0.185 & -2.23 \\
\hline$\Delta \pi_{t-7}$ & -0.209 & -2.73 & -0.134 & -1.73 \\
\hline$\Delta \pi_{t-8}$ & -0.098 & -1.30 & -0.045 & -0.60 \\
\hline$\Delta \pi_{t-9}$ & -0.120 & -1.62 & -0.069 & -0.95 \\
\hline$\Delta \pi_{t-10}$ & -0.229 & -3.34 & -0.181 & -2.74 \\
\hline$\Delta \pi_{t-11}$ & -0.093 & -1.70 & -0.070 & -1.36 \\
\hline$\pi_{t-1}$ & & & -0.621 & -5.88 \\
\hline$p_{t-1}$ & & & -0.054 & -5.04 \\
\hline SE & 0.00356 & & 0.00329 & \\
\hline$\chi^{2}$ & & & 31.26 & \\
\hline
\end{tabular}

- $p_{t}=\log$ of price level, $\pi_{t}=p_{t}-p_{t-1}, u_{t}=$ unemployment rate, $p m_{t}=\log$ of the price of imports.

- Estimation method: ordinary least squares.

- Estimation period: 1955:3-2006:2 (204 obs.).

- When $p_{t-1}$ and $p_{t-2}$ are added in place of $\pi_{t-1}$ and $p_{t-1}$, the respective coefficient estimates are -0.675 and -0.621 with $t$-statistics of -5.90 and 5.88 . All else is the same.

- The $5 \% \chi^{2}$ critical value $=5.99 ; 1 \% \chi^{2}$ critical value $=9.21$.

(5.99 and 9.21), but they are still smaller than the computed value of 31.26. The two price variables are thus significant at the $99 \%$ confidence level even using the alternative critical values.

The above procedure treats $u$ and $p m$ as exogenous, and it may be that the estimated critical values are sensitive to this treatment. To check for this, the following two equations were postulated for $u$ and $p m$ :

$$
\begin{aligned}
p m_{t}= & a_{1}+a_{2} t+a_{3} p m_{t-1}+a_{4} p m_{t-2}+a_{5} p m_{t-3}+a_{6} p m_{t-4}+v_{t}, \\
u_{t}= & b_{1}+b_{2} t+b_{3} u_{t-1}+b_{4} u_{t-2}+b_{5} u_{t-3}+b_{6} u_{t-4}+b_{7} p m_{t-1} \\
& +b_{8} p m_{t-2}+b_{9} p m_{t-3}+b_{10} p m_{t-4}+\eta_{t} .
\end{aligned}
$$

These two equations along with Eq. (10) were taken to be the "model," and they were estimated by ordinary least squares along with Eq. (10) to get the "base" model. The error terms $\varepsilon_{t}, v_{t}$, and $\eta_{t}$ were then assumed to be multivariate normal with mean zero and covariance matrix equal to the estimated covariance matrix (obtained from the estimated residuals). Each trial then consisted of draws of the three error terms for each quarter and a dynamic simulation of the model to generate new data for $p, p m$, and $u$, from which the $\chi^{2}$ value was computed. The computed critical values were not very sensitive to this treatment of $\mathrm{pm}$ and $u$, and they actually fell slightly. The $5 \%$ value was 12.30 compared to 18.88 above, and the $1 \%$ value was 17.48 compared to 24.30 above. The U.S. data thus reject the dynamics implied by Eq. (10): $\pi_{t-1}$ and $p_{t-1}$ are significant when added to Eq. (10). 
Table 2

Outside-sample RMSEs

\begin{tabular}{|c|c|c|c|c|c|c|}
\hline & \multicolumn{6}{|c|}{ Quarters ahead } \\
\hline & \multicolumn{2}{|l|}{$p$} & \multicolumn{2}{|l|}{$\pi$} & \multicolumn{2}{|l|}{$\Delta \pi$} \\
\hline & 4 & 8 & 4 & 8 & 4 & 8 \\
\hline Eq. (10) & 1.93 & 4.62 & 2.73 & 3.49 & 2.17 & 2.16 \\
\hline Eq. (11) & 1.74 & 3.66 & 2.41 & 2.61 & 2.16 & 2.21 \\
\hline Eqs. (14) and (15) & 1.15 & 2.20 & 1.73 & 1.73 & 1.90 & 1.89 \\
\hline Eqs. (17) and (15) & 1.12 & 2.17 & 1.68 & 1.77 & 1.89 & 1.88 \\
\hline
\end{tabular}

- $p=\log$ of the price level, $\pi=\Delta p$.

- Prediction period: 1970:1-2006:2.

- Errors are in percentage points and are quarterly changes at annual rates for $\pi$ and $\Delta \pi$.

The dynamics of Eq. (10) can be further examined by adding only $\pi_{t-1}$. This breaks the summation restriction but not the other (price level) restriction. Although not reported in Table 1, when this is done, the sum of the $\delta_{i}$ coefficient estimates is 0.806 , which is considerably less than 1 . The sum is not, however, significantly less than one if the computed critical $\chi^{2}$ values are used. The $\chi^{2}$ value when $\pi_{t-1}$ is added is 7.55, and the computed $5 \%$ and $1 \%$ critical values are 9.00 and 13.28 , respectively. ${ }^{5} \pi_{t-1}$ is thus not significant at even the $5 \%$ level when added to Eq. (10). A further test is to add $p_{t-1}$ to Eq. (10) with $\pi_{t-1}$ already added. When this is done the $\chi^{2}$ value is 22.82 with computed $5 \% 1 \%$ critical values of 10.34 and 18.20 , respectively. ${ }^{6} p_{t-1}$ is thus significant when added to the equation with $\pi_{t-1}$ already added.

Another way to examine Eqs. (10) and (11) is to consider how well they predict outside sample. Focusing on outside-sample predictions reduces the chance of spurious results due to data mining. To examine these predictions, the following root mean squared error (RMSE) test was performed. Each equation was first estimated for the period ending in 1969:4 (all estimation periods begin in 1955:3), and a dynamic eight-quarter-ahead prediction was made beginning in 1970:1. The predicted values were recorded. The equation was then estimated through 1970:1, and a dynamic eightquarter-ahead prediction was made beginning in 1970:2. This process was repeated through the estimation period ending in 2006:1. Since observations were available through 2006:2, this procedure generated 146 one-quarter-ahead predictions, 145 two-quarter-ahead predictions, through 139 eight-quarter-ahead predictions, where all the predictions are outside sample. RMSEs were computed using these predictions and the actual values.

The actual values of $u$ and $p m$ were used for all these predictions, which would not have been known at the time of the predictions. The aim here is not to generate predictions that could have in principle been made in real time, but to see how good the dynamic predictions from each equation are conditional on the actual values of $u$ and $p m$.

The RMSEs are presented in the first two rows of Table 2 for the four- and eight-quarter-ahead predictions for $p, \pi$, and $\Delta \pi$. (Ignore the third and fourth rows for now.) Comparing the two rows (Eq. (10) versus (11)), the RMSEs for $\Delta \pi$ are similar, but they are much smaller for $p$ and $\pi$ for Eq. (11). The restrictions clearly lead to a loss of predictive power for the price level and the rate of inflation. It is thus the case that the addition of $\pi_{t-1}$ and $p_{t-1}$ to Eq. (10) has considerably increased the accuracy of the predictions, and so these variables are not only statistically significant but also important in a predictive sense.

\footnotetext{
${ }^{5}$ These critical values and the ones cited next were computed using equations (12) and (13).

${ }^{6}$ In this case the base equation for the computation of the critical values is Eq. (10) with $\pi_{t-1}$ added.
} 


\section{A price and wage equation specification}

Prior to the triangle model, separate price and wage equations were sometimes estimated in which prices affect wages and vice versa. Led by Gordon (1980), this specification gradually got replaced by looking only at the reduced-form equation for prices. In this section, I examine the price and wage equations in my U.S. macroeconometric model. This specification is not new-the original specifications goes back to Fair (1984)—but, as will be seen, it appears to dominate the price equations discussed in the previous section. The two equations are

$$
\begin{aligned}
& p_{t}=\beta_{0}+\beta_{1} p_{t-1}+\beta_{2}\left(w_{t}+d_{t}\right)+\beta_{3} p m_{t}+\beta_{4} u_{t}+\beta_{5} t+\varepsilon_{t}, \\
& w_{t}=\gamma_{0}+\gamma_{1} w_{t-1}+\gamma_{2} p_{t}+\gamma_{3} p_{t-1}+\gamma_{4} t+\mu_{t},
\end{aligned}
$$

where

$$
\gamma_{3}=\left[\beta_{1} /\left(1-\beta_{2}\right)\right]\left(1-\gamma_{2}\right)-\gamma_{1} .
$$

$w_{t}$ is the $\log$ of $\left(W_{t} / \lambda_{t}\right)$, where $W_{t}$ is the nominal wage rate and $\lambda_{t}$ is trend productivity (output per worker hour). $d_{t}$ is the $\log$ of $\left(1+D_{t}\right)$, where $D_{t}$ is the employer social security tax rate. It is possible that $u_{t}$ should be in the wage equation, but it will be seen below that it is not significant. Even if $u_{t}$ is in the wage equation, the two equations are identified because $p m_{t}$ is excluded from the wage equation and $w_{t-1}$ is excluded from the price equation.

The theory behind Eqs. (14) and (15) is presented in Fair (2004), and a briefer discussion is in Section 2 in Fair (2007). This discussion will not be repeated here. Firms are assumed to set prices and wages in a monopolistic competitive setting. Regarding the use of levels versus changes, the decision variables of a firm in the model are its price and wage levels. For example, the market share equations in the theoretical model have a firm's market share as a function of the ratio of the firm's price to the average price of other firms. These are price levels, and the objective of the firm is to choose the price level path (along with the paths of the other decision variables) that maximizes a multiperiod objective function. A firm decides what its price level should be relative to the price levels of other firms. A similar argument holds for the wage decision. This theory thus argues for the specification of price and wage equations in levels, which is what is done in Eqs. (14) and (15). Eqs. (14) and (15) can be thought of as aggregate approximations to firms' decision equations. How good an approximation is, of course, an empirical question.

The time trend in Eq. (14) is meant to pick up any trend effects on the price level not captured by the other variables. Adding the time trend to an equation like (14) is similar to adding the constant term to an equation specified in terms of changes rather than levels. The time trend will also pick up any trend mistakes made in constructing $\lambda_{t}$. If, for example, $\lambda_{t}=\lambda_{t}^{a}+\alpha_{1} t$, where $\lambda_{t}^{a}$ is the correct measure, then the time trend will absorb this error. A similar argument holds for the time trend in the wage equation (15). The coefficient restriction (16) insures that the real wage, $w_{t}-p_{t}$, depends on $w_{t-1}-p_{t-1}$, but not on $w_{t-1}$ or $p_{t-1}$ separately. It is not sensible that in the long run the real wage depends on the level of prices or wages.

In the US model Eqs. (14) and (15) are estimated by two stage least squares (2SLS). Eq. (14) is first estimated, and then the coefficient estimates of $\beta_{1}$ and $\beta_{2}$ are used in the constraint (16) to estimate (15). The estimation period for the present results is 1954:1-2006:2. The variables treated as endogenous in the estimation are $p_{t}, w_{t}, p m_{t}$, and $u_{t}$. All variables are assumed to be trend stationary. The first stage regressors are predetermined variables in the US model and are available on the website mentioned in the introductory footnote. The results of estimating Eqs. (14) and (15) are presented in Tables 3 and 4, respectively.

The coefficient estimates of the two equations are significant in Tables 3 and 4 . The first test of the wage equation in Table 4 is of the restriction (16). The improvement in the fit when the restriction is relaxed is negligible, with a $\chi^{2}$ value of only 0.002 . The restriction is thus not rejected. The second test is to add $u_{t}$ to the wage equation. For this test only the coefficient estimate of $u_{t}$ is presented. The coefficient estimate is not significant, with a $t$-statistic of -0.43 . If the unemployment rate is not in the wage equation, as this result suggests, then the price and wage equations together imply that a 
Table 3

Estimates of Eq. (14): Left-hand side variable is $p_{t}$

\begin{tabular}{|c|c|c|}
\hline Variable & Estimate & $t$-stat. \\
\hline cnst & -0.0395 & -3.66 \\
\hline$p_{t-1}$ & 0.8845 & 98.55 \\
\hline$w_{t}+d_{t}$ & 0.0350 & 3.20 \\
\hline$p m_{t}$ & 0.0507 & 22.42 \\
\hline$u_{t}$ & -0.1756 & -7.35 \\
\hline$t$ & 0.0003 & 9.82 \\
\hline SE & 0.00343 & \\
\hline \multicolumn{3}{|l|}{ Tests: } \\
\hline$u_{t}$ & -0.1494 & -5.58 \\
\hline$Y_{t} / Y_{T R E N D_{t}}$ & 0.0180 & 2.05 \\
\hline$u_{t}$ & -0.1890 & -6.19 \\
\hline$\left(Y S_{t}-Y_{t}\right) / Y S_{t}$ & 0.0144 & 0.85 \\
\hline$u_{t}$ & -0.2088 & -6.77 \\
\hline$\left(Y S S_{t}-Y_{t}\right) / Y S S_{t}$ & 0.0291 & 1.82 \\
\hline$u_{t}$ & -0.1744 & -7.23 \\
\hline lshare $_{t}$ & 0.0315 & 1.65 \\
\hline$p m_{t}$ & 0.0526 & 17.45 \\
\hline pcrudm $_{t}$ & -0.0030 & -0.95 \\
\hline$p m_{t}$ & 0.0510 & 20.69 \\
\hline pcrudo $_{t}$ & -0.0038 & -0.35 \\
\hline
\end{tabular}

- $p_{t}=\log$ of price level, $w_{t}=\log$ of the nominal wage divided by trend productivity, $d_{t}=\log$ of 1 plus the employer social security tax rate, $u_{t}=$ unemployment rate, $p_{t}=\log$ of the price of imports, $Y=$ output of the firm sector, YTREND = trend output of the firm sector, YS = potential output of the firm sector in the US model, YSS = potential output of the firm sector from peak-to-peak interpolations, lshare $=\log$ of the labor share of the nonfarm business sector, pcrudm $_{t}=\log$ of the crude materials producer price index, pcrudo $_{t}=\log$ of the crude petroleum producer price index.

- Estimation method: two stage least squares.

- Estimation period: 1954:1-2006:2 (210 obs.).

Table 4

Estimates of Eq. (15): Left-hand side variable is $w_{t}$

\begin{tabular}{lll}
\hline Variable & Estimate & $t$-stat. \\
\hline cnst & -0.0624 & -4.01 \\
$w_{t-1}$ & 0.9292 & 44.03 \\
$p_{t}$ & 0.7959 & 13.43 \\
$p_{t-1}$ & -0.7421 & $a$ \\
$t$ & 0.0001 & 2.93 \\
SE & & \\
& 0.00843 & \\
Tests: & & \\
Restriction & & $p$-value $=0.9689$ \\
$u_{t}$ & $\chi^{2}=0.002$ & -0.43 \\
\hline
\end{tabular}

a: Coefficient restricted.

- See notes to Table 3 for notation.

- Estimation method: Two stage least squares.

- Estimation period: 1954:1-2006:2 (210 obs.). 
demand change first affects prices, which then affect wages. Likewise, a change in the price of imports first affects prices and then wages.

The tests in the second half of Table 3 are of alternative measures of demand and alternative measures of cost shocks. For each test a new variable was added and the equation reestimated. For the demand-variable tests the coefficient estimates of $u_{t}$ and the new demand variable are presented, and for the cost-shock tests the coefficient estimates of $\mathrm{pm}_{t}$ and the new cost-shock variable are presented. The unemployment rate is always highly significant in the demand-variable tests. The only other variable that is significant is the ratio of output to trend output, which has a $t$-statistic of 2.05. The labor share variable stressed by Galí and Gertler (1999) is not significant. The unemployment rate thus clearly dominates the output and labor share variables. The two other measures of cost shocks, the crude materials producer price index and the crude petroleum producer price index, are completely dominated by the import price index, as can be seen at the bottom of $3 .^{7}$

Eqs. (14) and (15) can be compared to Eqs. (10) and (11) as to how well they explain the data by computing outside-sample RMSEs. For these calculations the beginning estimation quarter was 1954.1, and the first end estimation quarter was 1969.4. Each of the 146 sets of estimates used the 2SLS technique with the coefficient restriction imposed, where the values used for $\beta_{1}$ and $\beta_{2}$ in the restriction were the estimated values from Eq. (14). The same first stage regressors were used for these estimates as were used in the basic estimation of the equations. The predictions of $p$ and $w$ from Eqs. (14) and (15) were generated using the actual values of $u$ and $p m$, just as was done for Eqs. (10) and (11).

The RMSEs are presented in the third row in Table $2 .^{8}$ The results show that the RMSEs using Eqs. (14) and (15) are noticeably smaller than those using even Eq. (11). For the eight-quarter-ahead prediction, for example, the RMSE for $p$ is 2.20 versus 3.66 for Eq. (11), and the RMSE for $\pi$ is 1.73 versus 2.61 for Eq. (11). Even for $\Delta \pi$ the RMSE using Eqs. (14) and (15) is smaller: 1.88 versus 2.21 for Eq. (11). The structural price and wage equations clearly do better than even the price equation with the NAIRU restrictions relaxed. These results thus call into question the movement away from the estimation of structural price and wage equations to the estimation of reduced-form price equations. Considerable predictive accuracy is lost when this is done.

\subsection{Functional form for the unemployment rate}

The specification that the unemployment rate enters linearly in Eq. (14) is not likely to be sensible at low values of the unemployment rate. It is difficult to test for nonlinear effects because there are very few observations of low unemployment rate values. Nevertheless, I did try various functional forms for the unemployment rate, like $\log u_{t}, 1 / u_{t}, \log \left(u_{t}-\beta_{6}\right)$, and $1 /\left(u_{t}-\beta_{6}\right)$, where $\beta_{6}$ was taken to be values between 0.01 and 0.03 . Better results were obtained using the log form than the reciprocal form. In particular, $\log \left(u_{t}-\beta_{6}\right)$ seemed to work well for different values of $\beta_{6}$. To test this further, the following equation was estimated by nonlinear 2SLS:

$$
p_{t}=\beta_{0}+\beta_{1} p_{t-1}+\beta_{2}\left(w_{t}+d_{t}\right)+\beta_{3} p m_{t}+\beta_{4} \log \left(u_{t}-\beta_{6}\right)+\beta_{5} t+\varepsilon_{t},
$$

where $\beta_{6}$ is also estimated. The estimates are presented in Table 5. The estimate of $\beta_{4}$, the coefficient multiplying $\log \left(u_{t}-\beta_{6}\right)$, and the estimate of $\beta_{6}$ are highly correlated, and so the precision of the two estimates is not high. Table 5 shows that the $t$-statistic for $\log \left(u_{t}-\beta_{6}\right)$ is only -1.13 and the $t$-statistic for $\beta_{6}$ is only 0.52 . However, the estimate of $\beta_{6}$ of 0.0163 is sensible, and the fit of this equation is better than that in Table 3 .

\footnotetext{
${ }^{7}$ Two other tests were performed for Eq. (14). First, the lagged values $p_{t-1}, w_{t-1}+d_{t-1}, p m_{t-1}$, and $u_{t-1}$ were added to the equation, and they were not jointly significant ( $p$-value of 0.272 ). Second, the equation was estimated under the assumption of fourth order serial correlation of the error term, and the four serial correlation coefficient estimates were not jointly significant ( $p$-value of 0.121). These two tests are rather strong tests of the dynamic specification of Eq. (14). Two other tests were also performed for Eq. (15). First, $w_{t-2}-p_{t-2}$ was added, and it was not significant ( $p$-value of 0.228 ). Second, the equation was estimated under the assumption of fourth order serial correlation of the error term, and the four serial correlation coefficient estimates were not jointly significant ( $p$-value of 0.282 ).

${ }^{8}$ Although predictions of both $p$ and $w$ are generated from this procedure, only the results for $p$ are presented in Table 2.
} 
Table 5

Estimates of Eq. (17): Left-hand side variable is $p_{t}$

\begin{tabular}{lrr}
\hline Variable & Estimate & $t$-stat. \\
\hline Nonlinear 2SLS & & \\
cnst & -0.0683 & -3.26 \\
$p_{t-1}$ & 0.8807 & 95.50 \\
$w_{t}+d_{t}$ & 0.0410 & 3.51 \\
$p m_{t}$ & 0.0500 & 21.06 \\
$\log \left(u_{t}-\beta_{6}\right)$ & -0.0073 & -1.13 \\
$\beta_{6}$ & 0.0163 & 0.52 \\
$t$ & 0.0003 & 9.35 \\
& & \\
SE & 0.00339 & \\
& & \\
Linear $2 S L S$ & & -3.49 \\
cnst & -0.0600 & 97.54 \\
$p_{t-1}$ & 0.8816 & 3.55 \\
$w_{t}+d_{t}$ & 0.0394 & 22.45 \\
$p m_{t}$ & 0.0503 & -1.55 \\
$\log \left(u_{t}-0.0163\right)$ & -0.0053 & 9.62 \\
$t$ & 0.0003 & -0.61 \\
$u_{t}$ & -0.0507 & \\
SE & & \\
\hline
\end{tabular}

- See notes to Table 3 for notation.

- Estimation period: 1954:1-2006:2 (210 obs.).

To test this nonlinear specification further, $\beta_{6}$ was restricted to be 0.0163 , and the equation was estimated with both $\log \left(u_{t}-0.0163\right)$ and $u_{t}$ added. These results are presented in the second half of Table 5. The $t$-statistic for $\log \left(u_{t}-0.0163\right)$ is -1.55 , and the $t$-statistic for $u_{t}$ is -0.61 . This is thus a slight evidence in favor of the nonlinear specification. As a final test, outside-sample RMSEs were computed using Eqs. (17) and (15), and these are reported in Table 2. The RMSEs for this specification are very close to those for Eqs. (14) and (15), and it is clear that these results cannot discriminate between the two specifications.

Given that there is at least slight support for the nonlinear specification, it is interesting to examine the dynamic properties of Eqs. (17) and (15) for different values of the unemployment rate. For this specification the effects on prices and wages from a change in the unemployment rate will depend on the initial level of the unemployment rate. Table 6 reports the results of permanently decreasing the unemployment rate by 0.005 percentage points from various levels. Take the first column, where the initial level of $u$ is 0.08 . Eqs. (17) and (15) were first solved dynamically using $u_{t}=0.080$ for all periods, and then they were solved using $u_{t}=0.075$ for all periods. The values in Table 6 are the differences in the two solution values for each period. (These differences do not depend on the values of the other variables in the equations as long as the values do not differ between the two solutions.)

The effects of the change on the price level and the inflation rate are presented in Table 6 for the first 12 quarters after the change. At the initial level of $u_{t}=0.050$ the price level is higher after a year by 0.43 percentage points. This increases to 0.63 for an initial level of 0.040 , to 1.20 for an initial level of 0.030 , and to 2.28 for an initial level of 0.025 . These values suggest that at least at around $u_{t}=0.040$ a change of this sort would likely trigger a substantial Fed reaction to cool off the economy, which is, of course, why there are so few very low values of the unemployment rate.

The long run effects of the change in the unemployment rate in Table 6 are for the price level to be permanently higher and for the inflation rate to go back to the rate that existed in the base case, i.e., no permanent change in the inflation rate. This is a consequence of the specification of Eqs. (17) and 
Table 6

Effects of a permanent change in $u$ of 0.005: Eqs. (17) and (15) used

\begin{tabular}{|c|c|c|c|c|c|c|c|c|c|c|}
\hline \multirow[t]{2}{*}{ Quar. } & \multicolumn{2}{|c|}{$u=0.080$} & \multicolumn{2}{|c|}{$u=0.050$} & \multicolumn{2}{|c|}{$u=0.040$} & \multicolumn{2}{|c|}{$u=0.030$} & \multicolumn{2}{|c|}{$u=0.025$} \\
\hline & $a$ & $b$ & $a$ & $b$ & $a$ & $b$ & $a$ & $b$ & $a$ & $b$ \\
\hline 1 & 1.0006 & 0.25 & 1.0012 & 0.49 & 1.0018 & 0.72 & 1.0034 & 1.37 & 1.0065 & 2.58 \\
\hline 2 & 1.0012 & 0.23 & 1.0023 & 0.44 & 1.0034 & 0.65 & 1.0066 & 1.25 & 1.0124 & 2.35 \\
\hline 3 & 1.0017 & 0.20 & 1.0033 & 0.40 & 1.0049 & 0.59 & 1.0094 & 1.14 & 1.0178 & 2.14 \\
\hline 4 & 1.0022 & 0.19 & 1.0043 & 0.37 & 1.0063 & 0.54 & 1.0120 & 1.03 & 1.0228 & 1.94 \\
\hline 5 & 1.0026 & 0.17 & 1.0051 & 0.33 & 1.0075 & 0.49 & 1.0144 & 0.94 & 1.0273 & 1.77 \\
\hline 6 & 1.0030 & 0.15 & 1.0058 & 0.30 & 1.0086 & 0.45 & 1.0166 & 0.86 & 1.0314 & 1.61 \\
\hline 7 & 1.0033 & 0.14 & 1.0065 & 0.28 & 1.0097 & 0.41 & 1.0186 & 0.78 & 1.0352 & 1.46 \\
\hline 8 & 1.0036 & 0.13 & 1.0072 & 0.25 & 1.0106 & 0.37 & 1.0204 & 0.71 & 1.0387 & 1.33 \\
\hline 9 & 1.0039 & 0.12 & 1.0077 & 0.23 & 1.0114 & 0.34 & 1.0220 & 0.64 & 1.0418 & 1.21 \\
\hline 10 & 1.0042 & 0.11 & 1.0083 & 0.21 & 1.0122 & 0.31 & 1.0235 & 0.59 & 1.0447 & 1.10 \\
\hline 11 & 1.0044 & 0.10 & 1.0087 & 0.19 & 1.0129 & 0.28 & 1.0249 & 0.53 & 1.0473 & 1.00 \\
\hline 12 & 1.0047 & 0.09 & 1.0092 & 0.17 & 1.0136 & 0.25 & 1.0261 & 0.48 & 1.0497 & 0.91 \\
\hline
\end{tabular}

$a$ : New predicted price level divided by base predicted price level.

$b$ : New predicted inflation rate minus base predicted inflation rate (annual rate).

(15) in price and wage levels. The empirical support for the use of levels over changes is the significance of $p_{t-1}$ and $p_{t-2}$ when added to Eq. (10). On the theoretical side, if a firm is setting its price level in response to demand and its expectations of other firms' price levels, a shift in demand may simply lead in the long run to a permanently higher price level of the firm but not to a permanent increase in how much it raises its price level each period. Again, this story may break down at very high demand periods, but the Fed rarely allows this to happen.

\section{Conclusion}

As noted in Section 2, it will be interesting to see in future work if new-Keynesian Phillips curves can be developed that when embedded in a NK model yield significant FIML coefficient estimates of the expected future inflation variable under the assumption of rational expectations. These models need not be linear if the FT method can be used. The results so far, however, are not very encouraging, which argues for considering models not based on the assumption of rational expectations.

An alternative to the NKPC specification is the triangle model, but the results in Section 3 reject the dynamics implied by this model. When the price levels lagged once and lagged twice are added to the equation-Eq. (10) - they are highly significant. Also the outside-sample RMSEs are much better with the two variables added.

The price-wage model in Section 4 makes two basic changes from the triangle model: It adds a wage equation, and the specification is in level terms. In terms of outside sample RMSEs, this model is better than both Eq. (10) and Eq. (10) with the two lagged price levels added. The results in this section show that the unemployment rate dominates other measures of demand and that the price of imports dominates other measures of cost shocks. There is also some evidence of nonlinear effects of the unemployment rate on the price level at low values of the unemployment rate.

Finally, a comment on Eqs. (14) (or (17)) and (15) and the Lucas (1976) critique. These two equations are considered to be estimated decision equations of the firm sector. They are obviously only approximations, but they do not suffer from the Lucas critique if expectations are not rational. To the extent that expectations of future prices and wages affect current decisions, agents are assumed to form these expectations on the basis of past values, where the parameters multiplying these values are constant. Expectations are backward looking in this sense. The parameters in the expectation equations are assumed not to depend on the parameters in the model: Expectations are not model consistent (rational). In the specification of a decision equation to estimate, if expected 
future values influence the current decision (which is usually the case), these values are substituted out by replacing them with the lagged values upon which they are assumed to depend. The decision equation is then estimated with these values included. If the parameters in the expectation equations are constant, then this substitution does not introduce non-constant parameters in the decision equation. It is usually not the case that one can back out from the estimated decision equation the parameters of the expectations equations, but there is usually no need to do so. Under the above assumptions, expectations have been properly accounted for in the decision equation.

This treatment of expectations does not mean that policy changes have no effect on behavior. Say that the Fed announces a new policy regime, one in which it is going to weight inflation more than it has done in the past. If expectations are rational, this announcement will immediately affect them and thus immediately affect current decisions. Current decisions can be affected even before the Fed has actually changed the interest rate. In the treatment here expectations and thus decisions will be affected only after the interest rate has been changed. For example, an interest rate change affects demand, which affects output, which affects unemployment, which affects prices and wages. In this treatment decisions respond to policy changes, but only in response to actual changes in the policy variables. Announcements of new policy rules and the like have no effect on decisions because agents do not know the model and thus do not use it to form their expectations.

\section{Acknowledgments}

I am indebted to Jeff Fuhrer and Jesper Lindé for sending me their data.

\section{Appendix A. Data appendix}

Most of the data used in this paper are part of the US model in Fair (2004) and are available on the website mentioned in the introductory footnote. These data are listed in Table 7. The other variables used are the following. $\log$ YTREND was obtained from a regression of $\log Y$ on a constant and $t$ for the 1952:1-2006:2 period. YTREND is then exp(log YTREND). $\log$ YSS was obtained from a peak-to-peak interpolation of $\log Y$, where the peaks are 1953:2, 1962:2, 1966:2, 1973:2, 1989:2, 2000:2, and 2006:1. YSS is then exp(log YSS). pcrudm is the log of the crude materials producer price index, which is U.S. Bureau of Labor Statistics (BLS) series id WPUSOP1000, and pcrudo is the log of the crude petroleum producer price index, which is BLS series id WPU0561. lshare is the log of the labor share, which is also based on BLS data. The labor share is compensation divided by nominal output in the non-farm business sector, where compensation equals compensation per hour (COMPNFB) times hours of all persons (HOANBS) and nominal output equals output (OUTNFB) times the implicit price deflator (IPDNBS).

\section{Table 7}

The variables used

\begin{tabular}{ll}
\hline Paper & US Model-Fair (2004) \\
\hline$p=\log P F$ & $P F=$ private non-farm price deflator \\
$w=\log W F$ & WF = average hourly earnings excluding overtime of workers in the firm sector. \\
& Includes supplements to wages and salaries except employer contributions for social insurance \\
$d=\log (1+D 5 G)$ & $D 5 G=$ employer social security tax rate \\
$p m=\log P I M$ & $P I M=$ import price deflator \\
$u=U R$ & $U R=$ civilian unemployment rate \\
$Y=Y$ & $Y=$ output of the firm sector \\
$Y S=Y S$ & $Y S=$ potential output of the firm sector \\
$\lambda=L A M$ & $L A M=$ amount of output capable of being produced per worker hour \\
\hline
\end{tabular}




\section{References}

Blanchard, O.J., Galí, J., 2005. Real wage rigidities and the new Keynesian model. Discussion Paper No. 5375, Centre for Economic Policy Research, December 2005.

Fair, R.C., 1984. Specification, Estimation, and Analysis of Macroeconometric Models. Harvard University Press, Cambridge, MA.

Fair, R.C., 2004. Estimating How the Macroeconomy Works. Harvard University Press, Cambridge, MA.

Fair, R.C., 2007. Evaluating inflation targeting using a macroeconometric model. In: Economics-the Open-Access, OpenAssessment E-Journal, 2007-2008.

Fair, R.C., Taylor, J.B., 1990. Full information estimation and stochastic simulation of models with rational expectations. Journal of Applied Econometrics 5, 381-392.

Fuhrer, J.C., 1997. The (un)importance of forward-looking behavior in price specifications. Journal of Money, Credit, and Banking 29, 338-350.

Galí, J., Gertler, M., 1999. Inflation dynamics: A structural econometric analysis. Journal of Monetary Economics 44, $195-222$.

Gordon, R.J., 1980. Comments on George L. Perry, Inflation in theory and practice. Brookings Papers on Economic Activity, 249-257.

Kurmann, A., 2007. VAR-based estimation of Euler equations with an application to new Keynesian pricing. Journal of Economic Dynamics and Control 31, 767-796.

Lindé, J., 2005. Estimating new-Keynesian Phillips curves: a full information maximum likelihood approach. Journal of Monetary Economics 52, 1135-1149.

Lucas Jr., R.E., 1976. Econometric policy evaluation: A critique. In: Brunner, K., Meltzer, A.H. (Eds.), The Phillips Curve and Labor Markets. North-Holland, Amsterdam.

Rudd, J., Whelan, K., 2005. New tests of the new-Keynesian Phillips curve. Journal of Monetary Economics 52, $1167-1181$.

Rudd, J., Whelan, K., 2006. Can rational expectations sticky-price models explain inflation dynamics? The American Economic Review 96, 303-320.

Rudd, J., Whelan, K., 2007. Modeling inflation dynamics: A critical review of recent research. Journal of Money, Credit, and Banking 39 (Supplement), 155-170. 